Board of Governors of the Federal Reserve System

International Finance Discussion Papers

Number 572

November 1996

\title{
MONEY, POLITICS AND THE POST-WAR BUSINESS CYCLE
}

\author{
Jon Faust and John Irons
}

NOTE: International Finance Discussion Papers are preliminary materials circulated to stimulate discussion and critical comment. References to International Finance Discussion Papers (other than an acknowledgment that the writer has had access to unpublished material) should be cleared with the author or authors. 


\begin{abstract}
While macroeconometricians continue to dispute the size, timing, and even the existence of effects of monetary policy, political economists often find large effects of political variables and often attribute the effects to manipulation of the Fed. Since the political econometricians often use smaller information sets and less elaborate approaches to identification than do macroeconometricians, their striking results could be the result of simultaneity and omitted variable biases. Alternatively, political whims may provide the instrument for exogenous policy changes that has been the Grail of the policy identification literature. In this paper, we lay out and apply a framework for distinguishing these possibilities. We find almost no support for the hypothesis that political effects on the macroeconomy operate through monetary policy and only weak evidence that political effects are significant at all.
\end{abstract}




\title{
Money, politics and the post-War business cycle
}

\author{
Jon Faust and John Irons ${ }^{1}$
}

Suppose you were looking for a simple economic rule of thumb for remembering what party held the White House in each post-War presidential term. You would be hard pressed to do better than the following rule: if a recession starts in the first 6 quarters of term, its a Republican; otherwise its a Democrat. This rule calls 12 of 13 presidential terms - its one faux pas is calling Reagan's second term Democratic.

Political economists have uncovered many such striking associations between political variables and headline measures of macroeconomic well-being such as economic growth, unemployment, and inflation. Evaluating the size and cause of such effects has generated a flourishing literature. ${ }^{2}$ One leading explanation for the associations in U.S. data seems to be the political manipulation of monetary policy. ${ }^{3}$

These political results are all the more striking from the perspective of the venerable and growing macroeconometric literature on the effects of monetary policy. This literature continues to show little agreement on the size, timing, and even the existence of effects of monetary policy. ${ }^{4}$ The conflict between the political econo-

\footnotetext{
${ }^{1}$ Faust is a staff economist at the International Finance Division of the Board of Governors of the Federal Reserve System. Irons is in the Economics Department at MIT. The authors thank Olivier Blanchard, Mike Gibson, Beth Ingram, Ed Leamer, Torsten Persson, Lars Svensson, the econometrics lunch group and workshop at the Federal Reserve Board as well as seminar participants at Duke, Indiana U., MIT, Northwestern, and North Carolina State for useful comments. Part of this work was completed while Faust was a visitor at the Institute for International Economic Studies in Stockholm. Irons thanks the National Science Foundation for Financial Support. The views in this paper are solely the responsibility of the authors and should not be interpreted as reflecting the views of the Board of Governors of the Federal Reserve System or of any other person associated with the Federal Reserve System.

2 Friedlaender, 1973; Nordhaus, 1975; Hibbs, 1977, 1987; MacRae, 1977; Frey and Schneider, 1978; McCallum, 1978; Tufte, 1978; Golden and Poterba, 1980; Beck, 1982; Browning, 1985; Allen, 1986; Chapell and Keech, 1978; Richards, 1986; Soh, 1986; Alesina and Sachs, 1988; Haynes and Stone, 1989,1990; Bizer and Durlauf, 1990; Ellis and Thoma, 1991; Allen and McCrickard, 1991; Gärtner and Wellershoff,1991; Havrilesky and Gildea, 1991a,b; Alesina and Roubini, 1992; Alesina, Londregan and Rosenthal, 1993; Hess, 1993; Klein, 1993; Alesina and Rosenthal, 1995; Bange, Bernhard, and Granato, 1995.

${ }^{3}$ e.g., Alesina and Sachs, 1988; Alesina and Rosenthal, 1995.

${ }^{4}$ Recent contributions include Bernanke and Blinder, 1992; Christiano and Eichenbaum, 1992; Leeper and Gordon, 1992, 1994; Christiano, Eichenbaum, and Evans, 1994; Hoover and Perez 1994a,b; Leeper, 1993; Romer and Romer, 1989,1990,1994; Sims, 1992; Sims and Zha, 1994; Strongin 1995 .
} 
metric results showing strong and consistent effects of politically driven monetary policy and the less definitive macroeconometric results almost certainly stems from blind spots in each approach.

The macroeocnometric literature pays elaborate attention to questions of identification, attempting to sort out the effects of policy from among the myriad interactions in a simultaneous system. Political variables are seldom if ever explored. In contrast, virtually all of the work linking politics to economic outcomes is bi-variate, linking one economic variable with one political variable (many such bi-variate relations are examined). ${ }^{5}$ Further, the political variable-either a dummy variable for the party in power, or some other measure of the political state-is generally treated as exogenous, despite the fact that endogeneity of political variable is clear a priori and well documented. ${ }^{6}$ There is also a literature relating politics to instruments of monetary policy, rather than macroeconomic outcomes. ${ }^{7}$ In this literature, some indicator of policy stance is modelled as a function of several economic and political variables. The link from instrument to economy is generally not investigated, and once again the political variables are often taken to be exogenous.

In light the blind spots in the literatures, we see two obvious possibilities for resolving the conflicting results. The macroeconometricians could be correct if the political results were all due to simultaneous equations bias and omitted variable bias. The dramatic results advanced by the political economists, however, make it plausible that more sophisticated econometric techniques will not eliminate the effects. In this case, the formal interpretation is that the political variables provide the instrument needed for identification: if the party in power determines the path of monetary policy, and the party is itself chosen (at least in part) based on noneco-

\footnotetext{
${ }^{5}$ Among the papers listed above, Friedlaender, 1973, is the clearest exception to the bi-variate norm. Even when the information set includes more than one macroeconomic variable, as in Gärnter and Wellershoff, 1991, it seldom includes the major determinants found in typical macroeconomic models.

6 Results on either side of this issue includes Stigler, 1973; Tufte, 1978; Hibbs, 1987; Fair,1978,1982; Gleisner, 1992; Alesina, Londregan and Rosenthal, 1993; Haynes and Stone, 1994; Alesina and Rosenthal, 1995; Granato and Suzuki, undated.

7 e.g., Golden and Poterba, 1980; Beck, 1982; Allen, 1986; Richards, 1986; Allen and McCrickard,1991; Ellis and Thoma, 1991; Bange, Bernhard, and Granato, 1995.
} 
nomic factors, then political variables may be the instruments for exogenous policy changes that has been the Grail of the policy identification debate.

This paper provides a theoretical econometric framework for addressing issues of causality from politics to the economy. This framework sheds some light on strengths and weaknesses of earlier work and provides the basis for a new look at the evidence. While the basic approach is very general, the particular application should be viewed as a first step and has several limitations. We consider only one political variable, the party in the White House, and ignore Congressional issues raised, e.g., by Alesina, Londregan and Rosenthal [1993]. We do not allow for systematic differences across administrations of a given party, which have been found to be important in some work [e.g., Beck, 1982]. Because we are focussing on special issues that arise under a fixed, long election cycle, we consider only U.S. data. For the most part, we consider only the major macroeconomic variables: output, employment, interest rates, money, and inflation. In focussing on the links from politics to the economy, we do not model the reaction functions as carefully as work focussing on reaction functions exclusively. Further, we limit ourselves largely to linear effects. Finally, we consider only data since $1948 .^{8}$

We find most support for the view that political effects on the economy, if they exist, are small and difficult to measure with confidence. Thus, omitted variable and simultaneous equation bias appear to be a large problem in the political econometric work finding large and systematic effects. We find some evidence that the party in power affects output growth-the party in power seems to help some in accounting for the recession that has historically followed the election of Republicans. This evidence is very weak and not robust to various reasonable alterations of the specification. We find almost no support for the view that any political effects operate through monetary policy. Thus, the reaction of interest rates, money, and inflation to the party in power appear economically small and statistically insignificant.

The results cast strong doubt on earlier results in the political econometric lit-

${ }^{8}$ Good a priori reasoning and econometric work support the view that there is little hope of fitting a stable, linear macroeconomic model for the entire century. 
erature that ignore the sources of bias discussed above. Because of the limitations outlined above, these results should be interpreted cautiously. A reasonable interpretation is that political effects are not large and systematic enough to be measured using relatively standard methods and macroeconomic information sets. Finding those effects will either require putting more structure on the problem in the form of a priori assumptions, using more powerful statistical methods, or bringing different information to bear.

In section 1, we review the theories and present a preliminary look at the data. Section 2 lays out our theoretical framework; Section 3 presents evidence from multivariate systems, and Section 4 concludes.

\section{A preliminary look at the theories and data}

\subsection{Political business cycle theories}

There is a wide range of theories about the links between politics and the economy. Alesina and Rosenthal [1995] provide a good summary. For our purpose, a coarse characterization will be sufficient.

The first important distinction is whether the theories focus on partisan differences in the control of instruments or on behavior that should be common to the parties. For example, Nordhaus's [1975] theory posits that either party in power should stimulate the economy before elections to enhance its election prospects by a myopic electorate. Partisan theories [such as Hibbs, 1977] posit that the parties should control the instruments according to different objective functions, implying that the instruments and the economy should behave differently under the two parties.

The second distinction is whether the stochastic nature of election outcomes is a crucial part of the theory. Under both Nordhaus's and Hibbs's theories, the party in power is stochastic, but this feature plays no central role in the predictions of the theory. In contrast, in Alesina's [1987] rational partisan theory, crucial implications turn on the effects of surprise changes in policy that come from election surprises. 
In particular, the parties implement different preferred average rates of inflation. A surprise election outcome in favor of Democrats leads to a surprise increase in inflation, which has the textbook stimulative effects on the economy.

From this characterization, a few gross facts are clear. We wish to have an approach that allows us to identify systematic changes in instruments and outcomes that vary with the deterministic election cycle. These effects may or may not vary by party. We also want to have an approach that allows us to identify the effects of election surprises, where these effects may also vary by party. Below, we derive an econometric framework that will accommodate these desiderata.

Although our framework would allow it, we do not specify formal representations of the theories and test them directly. Formal models must abstract from myriad issues present in reality, and any direct test of those model must, thereby, be viewed as a test of the joint hypotheses imbedded in the core of the formal model along with the auxiliary simplifying assumptions. Such tests shed little light on whether the core insights of the model are valid. Below we derive and test hypotheses associated with core implications of models. Further work sharpening these hypotheses might well be warranted.

\subsection{A preliminary look at the real variables}

We begin our examination of the data with some graphs that highlight the associations between political and economic variables and suggest pitfalls in trying to identify political effects on the economy. We focus on the period $1948 \mathrm{q} 1$ to $1995 \mathrm{q} 2$, which includes thirteen presidential terms (the first and last terms are incomplete). Of the thirteen terms, 7 are Republican; the parties came in the order D D R R D D R R D R R R D. Throughout, we take no account of the fact that Kennedy and Nixon served incomplete terms.

Figure 1 shows the average unemployment rate by party beginning 3 quarters before taking office through the end of the 4-year cycle. The data are averaged over 
the presidential terms in our sample. ${ }^{9}$ On entering the White House, Republicans are greeted by an unemployment rate about one percentage point lower than are Democrats; the rate begins to rise sharply in the third quarter in office and, by the sixth quarter, has begun to stabilize at a level that is more than a percentage point higher than on inauguration day. The opposite pattern is shown under Democrats, the rate falling by more than a percentage point before stabilizing.

Because averages can be dominated by outliers, we examine the median and interquartile range of the unemployment rate under the two parties (Figure 2). For each party, the time-series line connects the median, and the vertical bar gives the interquartile range. The interquartile range for the Democrats is displaced slightly to the left of the relevant quarter, while that for the Republicans is displaced to the right. The differences in the unemployment rates under the two parties are quite broad based. The median Republican shows a lower unemployment rate than the $25^{t h}$ percentile Democrat until the cross-over point in quarter 5, after which the median Republican is above the $75^{\text {th }}$ percentile Democrat. In 7 of the final 9 quaters of term, the $75^{\text {th }}$ percentile Democrat has a lower unemployment rate than the $25^{t h}$ percentile Republican.

As the unemployment rate moves sharply in opposite directions in quarters $3-5$ under the two parties, growth in hours of employment diverges widely (Figure 3 ). This widely divergent hours growth implies widely divergent output growth (Figure 4). ${ }^{10}$ Average output growth during quarters 3 and 4 is 5.3 percent under Democrats and -1.6 percent under Republicans-a difference of about seven percentage points.

The negative growth early in Republican administrations generally marks an NBER business cycle peak. We noted above that 6 of 7 Republicans and no Democrats had recessions start in the first 6 quarters of term. Only two of 6 Democrats had recessions begin in their terms: 1948q4 came at the end of Tru-

\footnotetext{
${ }^{9}$ Throughout, the quarters of the term are numbered from zero in the quarter of regularly scheduled inaugurations.

${ }^{10}$ Analogous pictures show a similarly robust pattern in consumption (with a median difference about half as large as for income) and investment (with a median difference over twice as large), but not in government spending.
} 
man's first term; 1980q1 began Carter's credit control recession.

\subsection{Nominal variables}

Republicans come into office to higher interest rates than Democrats; rates fall under Republicans as the economy slows, and rise under Democrats as it accelerates. In the second half, the differences between the parties are not robust (Figure 5). Note that this pattern in the interest rates is about what one might have expected from looking at the real variables, without knowing that the sample has been sliced by party. Of course, this fact would be missed in a univariate system.

The median inflation rate is higher when Republicans come into office and falls slightly over the term; the rate under Democrats rises during the term (Figure 6). After quarter 5, however, the differences are not robust. While inflation is rising steadily under Democrats in quarters 0 through 6 , the M2 growth rate is falling (Figure 7).

\subsection{Implications for more formal analysis}

While these results are tantalizing, they both demand careful statistical analysis and portend complex problems for the analyst. Two facts are clear: First, indicator variables for the party in power and stage in the presidential term are correlated with a wide range of nominal and real economic variables. Second, economic variables-particularly unemployment and interest rates-at the time of the election are correlated with the subsequent election outcome. These two facts can be summed up in the claim that there is a rich simultaneity with both rich lead and lag relations among the macroeconomic and political variables.

This rich simultaneity suggests that omitted variable bias and simultaneous equations bias will be major concerns in any work relating endogenous political variables to macroeconomic variables. While the association between party in power and the unemployment rate might be due to political manipulation of policy, it might just as well be due to causality from the economy to the party in power. Suppose the 
electorate chooses a Republican to run the country when the unemployment rate is below the natural rate and Democrats when it is above. If the unemployment rate is stationary, below average unemployment rates are naturally followed by rising rates. This might account for Figure 1 without relying on any causality from politics to the economy. On the other hand, if this reverse causation from economy to politics is to account for Figure 1, it must be the case that, in effect, the electorate can forecast one percentage point rises in the unemployment rate about a year in advance with great accuracy. Otherwise, they could not reliably put Republicans in office when such a rise is coming. It is not clear that unemployment rate rises are sufficiently predictable.

A somewhat richer illustration of problems measuring political effects comes from recent empirical work by Alesina and Rosenthal [1995] explaining inflation in terms of its own past and the party in power. In support of the claim that Democrats implement higher rates of inflation than Republicans, Alesina and Rosenthal cite the following regression:

$$
\begin{aligned}
I_{t}= & \underset{(5.4)}{1.2}+\underset{(17.4)}{1.3} I_{t-1}-\underset{(-2.9)}{0.3} I_{t-2}+\underset{(0.7)}{0.1} I_{t-3} \\
& -\underset{(-2.4)}{0.2} I_{t-4}-\underset{(-4)}{0.6} \mathrm{BW}-\underset{(-2.5)}{0.3} \operatorname{Repub}_{t-3}+\underset{(2.9)}{0.7} \mathrm{oil}_{t}
\end{aligned}
$$

(We produced these results, which very nearly replicate those of Alesina and Rosenthal.) In this regression, $I$ is annual CPI inflation, BW is a dummy variable that is one under the Bretton Woods system (through 1971) and zero otherwise, Repub is a variable that is one under Republicans and zero otherwise, and oil is a dummy variable that is one during $1973 \mathrm{q} 3-1974 \mathrm{q} 4$ and $1979 \mathrm{q} 4-1980 \mathrm{q} 4$. The sample period is 1949q1-1991q4; $t$-statistics are under the coefficients. Alesina and Rosenthal interpret the coefficient on Repub as evidence that Republicans implement lower inflation rates than Democrats, and that the effect begins to operate after three quarters in office.

Since the Repub dummy is endogenous we might worry that it is standing in for other macroeconomic variables that are important in determining inflation. For 
example, if the evolution of inflation depends on labor market tightness, as it does in a wide range of theoretical models, then Figures 1 and 2 suggest that the Repub dummy may enter this regression significantly acting as a crude proxy for current and past labor market tightness. ${ }^{11}$ If we suspect that the Repub dummy is a proxy for economic variables then we might expect $16^{\text {th }}$ order serial correlation in this regression - the macro variables move smoothly, but the dummy is constant for 16 quarters at a time. The LM test for absence of $16^{\text {th }}$ order serial correlation rejects at less than the 0.01 percent level. We add enough lags of inflation to eliminate the symptoms of serial correlation (13 lags) and include one lag of growth in hours to allow for an association between labor market tightness and inflation. In this regression, hours enters the regression very significantly (coefficient $0.04, t$-statistic 3.8) and the effect of the political dummy falls to one-sixth its previous magnitude and becomes statistically insignificant (coefficient -0.05 , $t$-statistic -0.7 ).

We present this brief result not because this is our preferred inflation equation, but to illustrate a general and important point:

Due to simultaneous equations and omitted variable bias, there is little a priori reason to expect robustness of political business cycle results that are based on a small macroeconomic information set and that treat political variables as exogenous.

In the following section, we lay out a framework for dealing with these problems.

\section{Specification and identification of a simultaneous system of macroe- conomic and presidential cycle variables}

The political variable considered here provides some special opportunities and special problems, each of which stem from the fact that the party in power takes on only two values and changes only every 16 quarters. The framework we adopt is quite general, but the particular implementation we choose is designed to be the simplest

\footnotetext{
11 Note that using lagged values as instruments might solve the simultaneity problem (if the instruments are valid), but will not solve the problem stemming from omitting serially correlated variables.
} 
possible generalization of the identified vector autoregression (VAR) approach. We choose this implementation because it provides both a simple and a natural starting point given the current prominence of VAR work for identifying the effects of monetary policy.

\subsection{Deriving and identifying the standard VAR}

Take one political variable $z_{t}$ and an $(n \times 1)$ vector of macroeconomic variables $X_{t}$, and posit that these variables are determined by

$$
\left[\begin{array}{c}
z_{t} \\
X_{t}
\end{array}\right]=f\left(\tilde{z}_{t-1}, \tilde{X}_{t-1}, e_{t}\right)
$$

where $\tilde{X}_{t}=\left(X_{t}^{\prime}, X_{t-1}^{\prime}, \ldots, X_{t-p}^{\prime}\right)^{\prime}, \tilde{z}_{t}$ is similarly defined, and $e_{t}$ is a vector of exogenous shocks. For any plausible macroeconomic model, $f$ is nonlinear, but we typically take a linear approximation to the model to give ${ }^{12}$

$$
\left[\begin{array}{c}
z_{t} \\
X_{t}
\end{array}\right]=\alpha+B\left[\begin{array}{c}
\tilde{z}_{t-1} \\
\tilde{X}_{t-1}
\end{array}\right]+\varepsilon_{t}
$$

Equation (2) is a vector autoregression (VAR) and is often written,

$$
B(L)\left[\begin{array}{c}
z_{t} \\
X_{t}
\end{array}\right]=\alpha+\varepsilon_{t}
$$

where $L z_{t}=z_{t-1}$ and $B(L)$ is a matrix polynomial in $L$. The nonlinear model is (generically) identified [McManus, 1992], but in linearizing we take on an identification problem arising from the fact that $(3)$ is observationally equivalent to $C(L)\left[z_{t}, X_{t}^{\prime}\right]^{\prime}=c+\varepsilon_{t}^{*}$ where $C(L)=C B(L), c=C \alpha$ and $\varepsilon_{t}^{*}=C \varepsilon_{t}$, and $C$ is full rank. Each such $C$ gives a different identification of the system, and the response of the economy to a shock, say, in the political variable is different in each.

\footnotetext{
${ }^{12}$ We attempt to choose the approximation and some transform of the variables so that $\varepsilon_{t}$ has constant mean and variance, and is serially uncorrelated. The adequacy of the linear approximation is testable, and the evidence for nonlinearities in U.S. macroeconomic data has not been strong enough to justify abandoning the linear framework.
} 
In this paper, we only attempt to identify the effects on $X_{t}$ of an exogenous shift in the $z_{t}$ equation. Thus, we only identify the effects of an election shock. If we ignore the special properties of the $z_{t}$ variable, two assumptions will be sufficient for identification. First, assume that in each quarter, the value of the political variable $z_{t}$ is determined before any other variable. This suggests a block recursive structure of the economy as in Sims [1980a], in which $X_{t}$ does not enter the $z_{t}$ equation contemporaneously. Second, assume that $\varepsilon_{1 t}$ is orthogonal to all the other $\varepsilon$ s at all leads and lags. That is, we place $z_{t}$ first in a block recursive ordering of the VAR and assume that $\varepsilon_{1 t}$ is orthogonal to the remaining $\varepsilon_{j t}$ at $t$.

Under these assumptions, we can estimate the model and calculate the dynamic effects of a one-period exogenous shift in the $z_{t}$ equation. The dynamic effects of such a change on the $j^{\text {th }} X$ variable are summarized in an impulse response function, which is the sequence of numbers,

$$
a_{j i}=\kappa \partial X_{j t+i} / \partial \varepsilon_{1 t} \quad i=0,1, \ldots
$$

where $\kappa$ is an arbitrary scaling reflecting the size of the presumed exogenous shift. ${ }^{13}$ The scheme laid out in the following section is the natural generalization of this scheme to allow for the special nature of $z_{t}$.

\subsection{Taking account of the presidential cycle variable}

Our $z_{t}$ is an indicator for party in power and is equal to 1 if a Democrat is in the White House at $t$ and is zero otherwise. Thus, $z_{t}$ is discrete and changes only every 16 periods in quarterly data. To deal with these special features, define $q(t) \in\{0, \ldots, 15\}$ as the time $t$ quarter of the presidential term, numbering from zero. Now assume that $z_{t}$ evolves according to:

\footnotetext{
${ }^{13}$ The coefficient $a_{j i}$ (up to a proportionality factor) is given by $(1, j)^{\text {th }}$ element of the matrix $A_{i}$, where $A(L)=\sum_{m=0}^{\infty} A_{m} L^{m}$ and $A(L)=B(L)^{-1}$.
} 


$$
\begin{aligned}
& \text { i) } E_{t-1} z_{t}=z_{t} \quad \text { for all } t, q(t) \text {, } \\
& \text { ii) } z_{t}=z_{t-1} \quad \text { if } q(t) \neq 0 \text {, and } \\
& \text { iii) } E_{t-2}\left[z_{t}\right]=\Phi\left(\tilde{X}_{t-2}, z_{t-2}\right) \text { if } q(t)=0 \text {. }
\end{aligned}
$$

Thus, the party in power may change every 16 quarters; it is picked based on the economy 2 quarters earlier; and the outcome of the election is known one quarter before the president takes power. Further, the probability that a Democrat will win, based on the macroeconomic variables and the current party in power, is $\Phi\left(\tilde{X}_{t-2}, z_{t-2}\right)$. These assumptions would be exactly appropriate if the election were held October 1 and the president took power January 1. We will model as if this slightly modified timing were correct.

Now replace the general representation of the economy in (1) with,

$$
\begin{aligned}
z_{t} & = \begin{cases}z_{t-1} & \text { if } q(t) \neq 0 \\
\Phi\left(\tilde{X}_{t-2}, z_{t-2}\right)+u_{t-1} & \text { otherwise }\end{cases} \\
X_{t} & =G\left(q(t), z_{t+1}, z_{t}, \tilde{X}_{t-1}, \nu_{t}^{*}\right)
\end{aligned}
$$

In $G$, we allow the presidential party this quarter and next quarter to affect this quarter's economy. Of course, both of these values are always known, and the two can only differ in the final quarter of term. ${ }^{14}$ Why is $q(t)$ an argument of $G$ ? It will obviously be relevant under Nordhaus-style theories. It may also be relevant under rational partisan theories since political uncertainty is not homoskedastic through time. Macro variables will fail to be homoskedastic if political uncertainty has important effects on the economy.

Of course, some form of time homogeneity must be imposed. Notice that $\left(z_{t+1}, z_{t}, q(t)\right)$ form a triplet of discrete variables. It is natural to view this triplet as the state of the political economy at $t$ and to assume that the economy is homogeneous conditional on the political state. Call the set of the 34 possible values of

\footnotetext{
${ }^{14}$ Further, lags of $z_{t}$ could be included without changing the analysis.
} 
this state variable $\Omega .{ }^{15}$ We can re-write the $X$ equation as

$$
X_{t}=G_{s(t)}\left(\tilde{X}_{t-1}, \nu_{t}^{*}\right)
$$

where $s(t) \in \Omega$ is the political state at $t$. The evolution of the state variable is governed by (5) and the exogenous quarter-of-term variable. After linearizing, the analog of the macroeconomic VAR in (2) is now

$$
X_{t}=\alpha_{s(t)}+B_{s(t)} \tilde{X}_{t-1}+\nu_{t}
$$

This expression says that the VAR representation for $X_{t}$ has different $\alpha$ and $B$ coefficients depending on the value of the political state. One can also write system as,

$$
X_{t}=\sum_{\omega \in \Omega} \alpha_{\omega} d_{\omega, t}+\sum_{\omega \in \Omega} B_{\omega} d_{\omega, t} \tilde{X}_{t-1}+\nu_{t}
$$

where $d_{\omega, t}=1$ if $\omega=s(t) \in \Omega$ and $d_{\omega, t}$ is zero otherwise. Thus, $d_{\omega, t}$ is an indicator that is one if the state at $t$ is $\omega$ and zero otherwise. Equation (6) says that we simply need to take the standard macroeconomic VAR and angment it with political state dummy variables interacted with the intercept and with all the slope coefficients. These dummy variables are not exogenous, but since their values at $t$ are known at $t-1$, they are predetermined. Of course, the system still involves the nonlinear equation for $z_{t}$. We show below that we can do the inference we wish to do simply by estimating the augmented VAR and need not estimate the nonlinear part of the model.

The form of the augmented VAR is similar to the model estimated by Ellis and Thoma [1991]. Ellis and Thoma derived no structural interpretation on the form, however, and considered a very limited specification, and, hence, face the identification and omitted variable problems common in the rest of the literature. ${ }^{16}$

\footnotetext{
${ }^{15}$ For the first 15 quarters of the term $z_{t}=z_{t+1}$ and can take on two values; in the final quarter, there are four possible values.

${ }^{16}$ More specifically, Ellis and Thoma treated the $d$ variables as exogenous; they examined impulse responses derived from an arbitrary recursive ordering of the VAR attributing nothing to the shock in the $d$ variables. Their VAR included instruments of policy, but no macroeconomic variables that may be important in determining those instruments.
} 
It is clearly impossible to estimate the coefficients of (6) in the post-War macro data. The summation over $\Omega$ involves 34 possible values of the state variable. Thus, the political model involves 34 times the (already large) number of coefficients in a standard macroeconomic VAR. This parsimony problem is similar to the one faced in most macro applications, and we deal with it in a standard manner as outlined below.

\subsection{Hypotheses of interest}

The sketch of political theories above suggests three nested hypotheses regarding the augmented VAR model. At the coarsest level, we are interested in whether any political variables need to be included in macroeconomic models. In the augmented VAR this is a matter of whether coefficients can be constrained to be constant across the political state, $s(t)$. Thus, the hypothesis that the political state is irrelevant is:

$$
H_{0}: \alpha_{m}=\alpha_{n} \text { and } B_{m}=B_{n} \text { for all } m, n \in \Omega
$$

If $H_{0}$ does not hold, we can consider the Nordhaus theory in which economic activity may vary with quarter of term but not with the value of the party in power. Defining $Q(m)$ as the quarter of term in state $m$, the hypothesis is

$$
H_{1}: \alpha_{m}=\alpha_{n} \text { and } B_{m}=B_{n} \text { whenever } Q(m)=Q(n)
$$

Under $H_{1}$, we find quarter-of-term effects, but no partisan differences. Rejection of $H_{0}$ and $H_{1}$ is evidence of partisan effects:

$$
H_{2}: \alpha_{m} \neq \alpha_{n} \text { or } B_{m} \neq B_{n} \text { for some } m, n \text { with } Q(m)=Q(n)
$$

Sorting out whether these effects are due to surprise effects, as in the rational partisan theory, or due to differences in policy that do not have their effects through surprises does not involve simple restrictions on the coefficients. We can, however, look at the impulse response to election shocks to see if the pattern favors a particular interpretation. ${ }^{17}$

\footnotetext{
17 Even stronger evidence would come from seeing effects that differ with the degree of election surprise. Since we do not estimate the $z$ equation, we cannot pursue this angle here.
} 


\subsection{Identification in the augmented model}

Before we can test the hypotheses above, we must be able to form estimates that are arguably free from simultaneity bias. We now have a model comprised by a nonlinear model for $z_{t}$, which determines the $d_{m, t}$ variables, and (6), an augmented VAR. As in the discussion of the standard case outlined above, we rely on a block recursive structure of $z_{t}$ and $X_{t}$ and an orthogonality assumption. Under the assumed timing of events, $z_{t}$ belongs first in a causal ordering of the model. We must also assume that the election shock $u_{t}$ is uncorrelated with $\nu_{s}$ for all $s, t$. Economically, this amounts to the decision to attribute to the political variable any macroeconomic outcome that is correlated with the election surprise. This assumption would be inappropriate if variables other than $\tilde{X}_{t}$ that determine the outcome of the election at the end of period $t$ also directly affect the economy. Suppose, for example, that news arrives in the third quarter of an election year of the breakdown in some peace talks. The breakdown might well alter the re-election prospects of the president and also directly affect the economy through its effects on military procurements. ${ }^{18}$ While it is easy to come up with examples like this, it is more difficult to come up with such examples that systematically favor one party or the other, thus inducing a spurious correlation between party and economy. By considering a large range of economic variables, and by considering the sensitivity of the results to changes in the information set, we hope to minimize this risk.

Validity of these assumptions is sufficient to allow us to estimate consistently the augmented VAR for $X_{t}$ while including $z_{t}$ and $z_{t+1}$ (through the $d$ variables) in the equations. The final issues concerns calculating the response of macro variables to the election shock.

\footnotetext{
${ }^{18}$ Faust and Leeper [1993], building on Hansen and Sargent [1991b] and Marcet [1991], question assumptions about the correlation of structural shocks based on problems with time-aggregated data. Given the nature of the $z_{t}$ variable, these problems would not exist here if the election were in fact held on Oct. 1, and we believe that these effects will be small in practice.
} 


\subsection{The impulse response to election shocks}

Because the $z_{t}$ equation is nonlinear, several complications arise regarding what we mean by an impulse response function [see, e.g., Gallant, et al., 1993]. Several of these are simplified by limiting ourselves to a 16 quarter impulse response, starting in quarter 15 of a presidential term, which we also call quarter - 1 of the following term. Election shocks happen only at the beginning of quarter -1, implying that the process for $z_{t}$ and $z_{t+1}$ (and, hence, for the $d_{t}$ variables) is conditionally deterministic for quarters 0 through 14 of the term. The next shock happens at the beginning of quarter $15(=-1)$. Thus, the 16 quarter impulse response of the political state to an election shock at quarter - 1 is trivial and depends on no unknown parameters. Because no variables feed back on the $z_{t}$ equation for 16 quarters, we can also compute the 16 quarter impulse response of $X_{t}$ to an election shock without estimating the nonlinear $z_{t}$ equation.

What we report below for the impulse response of $X_{j t+i}$ to an election shock at the beginning of time $t$ is the sequence of numbers,

$$
a_{j i}=0.10 \frac{\partial E_{t-1} X_{j t+i}}{\partial E_{t-1} u_{t}} \quad i=0,1, \ldots, 15 .
$$

where $u_{t}$ is the exogenous shock to the election outcome. Note that a rise in $E_{t-1} u_{t}$ by 1 percentage point equals a 1 percentage point change in the probability that a Democrat will be elected. Thus, while the standard impulse response gives the response of $X_{j}$ to a one standard deviation change in some shock, the modified impulse response gives the response of $X_{j}$ to a 10 percentage point change in the public's subjective probability that a Democrat will take the White House at $t+1 .^{19}$ The impulse response is easily calculated (see the Appendix).

\footnotetext{
19 Much of the nonlinearity of the problem has disappeared in this formulation. It remains in the $z_{t}$ equation, however. Thus, given the history up through $t-1$, only one of two shocks $u_{t}$ can happen: $-\Phi$ or $1-\Phi$. In order to estimate the actual shocks that could have happened a $t-1$, we must estimate the $z_{t}$ equation. Further, there is no simple notion of variance decomposition in this setting.
} 


\section{Application: A multivariate model with political effects}

In this section, we estimate the augmented VAR. Our goals are to assess the importance of political variables in traditional macro models and to assess the role of the monetary policy channel in accounting for any political effects. Thus, we begin with a much studied VAR including four macroeconomic variables: three-month Treasury bill rate, M2, the CPI, and GNP. These variables will be referred to as R, M, P, and Y respectively. The RMPY system is a natural starting point. Some version of these variables is at the core of the Friedman and Schwartz [1963] analysis and variations of this basic VAR have been investigated extensively in assessing monetary policy effects [e.g., Sims 1980b, Sims 1994].

The baseline VAR for RMPY has all variables in levels and all variables except the interest rate in logarithms. The VAR includes a constant and three seasonal dummies. The theoretical framework suggests that we augment the standard VAR with slope and intercept dummies for each quarter of the term under each party. This model is too profligately parameterized to be of interest and is even too general to be the starting point of a Hendry-style general-to-specific model search [Hendry, 1995]. Instead we start with a fairly general model, from which we derive a parsimonious baseline model. After demonstrating the baseline results, we consider a number of changes to the baseline model in order to assess robustness.

The estimation period is $1953 \mathrm{q} 2$ to $1995 \mathrm{q} 2$, and the lag length of six for the macro variables was selected by serial correlation tests. For our starting point we considered only political intercept dummies. From the possible 34 dummies for

the $-1^{\text {th }}$ through $15^{\text {th }}$ quarters of term under each party, only a subset are linearly independent given the constant and seasonal dummies. We began with a maximal set of these dummies, which were not jointly significant at the 10 percent level, and very few of the individual coefficients were significant at the 10 percent level. Because of the large number of dummy variables in this regression, the test probably has low power to reject the hypothesis of no effects. Thus, we tried replacing the quarter-of-term variables for one of the parties at a time with year-of-term dummies. 
Using Republican year-of-term variables, the the political variables were not jointly significant. Using Democratic year-of-term variables, all the of year-of-term variables and most of the Republican quarter-of-term variables were significant at the 1 or 5 percent level. We took this as our baseline model.

Thus, the baseline augmented VAR includes in four intercept dummies, $d y_{1}$ through $d y_{4}$, that are zero except in the subscripted year of a Democratic administration; 15 dummies, $r q_{0}, \ldots, r q_{14}$, that are zero except in the subscripted quarter of Republican administrations; and $d q_{-1}$ and $r q_{-1}$ which are zero except in the quarter before a Democrat or Republican take office, respectively.

The model passes serial correlation tests (for first, fourth, and sixteenth order correlation) and heteroskedasticity tests (Table 1, column $i$ ). Given the minimal attempt to datamine for the best set of political variables, we take the baseline results as relatively strong statistical evidence against $H_{0}$ - the irrelevance of politics-in this model. Five of the 16 Republican dummies are significant at the 1 percent level; an additional seven are significant at the 5 percent level. The political variables are jointly significant at the 7 percent level. The test of $H_{1}$, the absence of partisan effects, rejects at the 3 percent level.

As the point estimates of dummy variables are almost impossible to interpret in a dynamic system, we turn now to the impulse response functions, which provide a much more interpretable picture of the economic significance of the political effects (Figure 8). The point estimate of the impulse response is indicated by the circle; and the lines are empirical 95 percent coverage intervals calculated using the Sims-Zha [1994] Bayesian bootstrap. ${ }^{20}$

The 10 percentage point rise in Democratic election prospects generates a rise of over half a percentage point in output growth over the first year in office, which dissipates by the end of the second year. This seems like a large effect, say, of electing a Democrat when the ex ante probability of doing so was 90 percent. The expected

\footnotetext{
${ }^{20}$ The procedure was implemented in Gauss by the authors. The procedure uses an ignorance prior described by Sims and Zha. As Sims and Zha note, there is currently no entirely satisfactory way to calculate classical confidence intervals on impulse responses.
} 


\begin{tabular}{|c|c|c|c|}
\hline $\begin{array}{l}\text { version } \\
\text { variable }\end{array}$ & $i$ & $i i$ & iii \\
\hline $\mathrm{rq}_{-1}$ & $*$ & & \\
\hline $\mathrm{rq}_{0}$ & $* *$ & & $* *$ \\
\hline $\mathrm{rq}_{1}$ & $* * *$ & $* *$ & $*$ \\
\hline $\mathrm{rq}_{2}$ & $* * *$ & $*$ & \\
\hline $\mathrm{rq}_{3}$ & $*$ & & $* * *$ \\
\hline $\mathrm{rq}_{4}$ & $* * *$ & $* * *$ & $* *$ \\
\hline $\mathrm{rq}_{5}$ & $* * *$ & $* *$ & \\
\hline $\mathrm{rq}_{6}$ & $* *$ & & $* *$ \\
\hline $\mathrm{rq}_{7}$ & $* *$ & $* *$ & \\
\hline $\mathrm{rq}_{8}$ & $* *$ & & \\
\hline $\mathrm{rq}_{9}$ & $* * *$ & $*$ & $* *$ \\
\hline $\mathrm{rq}_{10}$ & $* * *$ & $* *$ & \\
\hline $\mathrm{rq}_{11}$ & $* *$ & & \\
\hline $\mathrm{rq}_{12}$ & & & $*$ \\
\hline $\mathrm{rq}_{13}$ & $* * *$ & $* *$ & \\
\hline $\mathrm{rq}_{14}$ & $* *$ & & \\
\hline $\mathrm{dq}_{-1}$ & & & \\
\hline $\mathrm{dy}_{1}$ & $* *$ & & \\
\hline$d y_{2}$ & $* *$ & & \\
\hline $\mathrm{dy}_{3}$ & $* *$ & & \\
\hline $\mathrm{dy}_{4}$ & $* * *$ & & \\
\hline $\mathrm{BW}$ & & & $* *$ \\
\hline$z_{t} \times \mathrm{BW}$ & & & $* * *$ \\
\hline $\mathrm{D} 1980 \mathrm{q} 2$ & & $* * *$ & $* * *$ \\
\hline $\mathrm{D} 1980 \mathrm{q} 3$ & & & \\
\hline D1980q4 & & $* * *$ & *** \\
\hline $\begin{array}{l}\text { AR }(1-16) \\
\text { Hetero }\end{array}$ & & $* *$ & $* * *$ \\
\hline
\end{tabular}

Notes: ${ }^{* * *},{ }^{* *},{ }^{*}$, indicate significance at the 1,5 , and 10 percent levels, respectively. The significance tests are $\mathrm{F}$ tests for inclusion of all terms involving the variable in the model. The AR test reported is the standard LM test. The heteroskedasticity test essentially involves a regression of the squared errors from the model on the levels and squares of all the variables and provides a test of significance of the variables in this second stage regression. The significance levels are all for the $\mathrm{F}$ form of the statistic. Tests were reported by PC-FIML and are further explained in Doornik and Hendry [1994].

Table 1: Significance of political state variables in the baseline model 
3-month Treasury bill rate follows the pattern that might be expected if the output effect were due to a persistent surprise rise in money growth: interest rates fall for at least a year and then rise by a similar amount and stay higher. The effect, however, is quite small, less than 25 basis points in each direction. M2 growth shows only a small and brief rise, and inflation shows similarly small effects and no economically significant pattern at all. Thus, while the basic pattern of interest rates is roughly consistent with the election shock generating a monetary policy surprise, the effects on output are probably larger than one would expect for such a small change in interest rates, and money growth and inflation are not very supportive of the story.

These results are much less supportive of the partisan model operating through money supply shocks than those of Alesina and Sachs [1988] and Alesina and Rosenthal [1995]. Those results involved interpreting political dummy variables from univariate regressions directly without resolving the dynamic interactions among variables or attempting to isolate the surprise element that is central to the theory.

Taken at face value, the results present a puzzle. Figures 1 through 9 and Table 1 show evidence of strong effects of party on aggregate measures of economic activity. The channels through which policy causes these effects, however, are not clear from any of these sources of information. One possibility is that the effects operate through fiscal policy. This possibility seems unlikely to account for the recession that quickly follows Republican elections, since fiscal policy is slow to change. In any case, we investigate this channel in a separate paper [Faust and Irons, 1996], finding no clear evidence that fiscal policy accounts for the observed output effects.

An alternative possibility is that the political variables are proxying for some other source of variation in output. If this is the case, we might expect the results to change when the specification of the model is altered. Thus, we turn to the robustness of the baseline results. We investigate 5 basic VARs: 1) the baseline model, 2) substitute M1 for M2 in the baseline, 3) add log of hours of work to the baseline, 4) add the log of the producer price index for intermediate materials to the 
baseline, 5) add the producer price index for sensitive materials to the baseline. ${ }^{21}$ Model 2 is warranted because results are often sensitive to which monetary aggregate is chosen. Model 3 is suggested by the effect of hours growth in the Alesina Rosenthal regression. Models 4 and 5 are motivated by work [e.g., Sims, 1992, Sims and Zha, 1994] arguing that commodity prices can substantially alter the results from RMPYtype VARs.

Three versions of each of the 5 models are run. Version $i$ involves no economic dummy variables. Version $i i$ is motivated by the fact that in the baseline model, $1980 \mathrm{q} 2$ is a large outlier. This is the quarter in which credit controls were enacted leading to the sharpest, shortest recession in U.S. history. ${ }^{22}$ It is clear that we cannot model the process leading to the imposition of credit controls, and it is important to investigate the sensitivity of the results to this episode. Thus, version $i i$ adds separate dummies, labelled D1980q2 through D1980q4, for the final three quarters of 1980. Version iii includes the credit control dummies and a dummy variable, BW, that is one up until 1972. Alesina and Rosenthal use this variable because the Bretton Woods system may have constrained inflation behavior before 1972. Many other important changes in the macroeconomy occurred at about this time: the onset of oil shocks and the productivity slowdown are two of the most important. To allow for the possibility that the parties had different mean inflation rates in the post-Bretton Woods system, but the same rate in under Bretton Woods, we also include the BW dummy interacted with the $z_{t}$ dummy.

The importance of these dummy variables is clear from their effects on the significance of the political variables in the baseline model (Table 1, columns ii and iii). For example, in versions $i i$ and $i i i$, none of the Democrat variables is significant at the 10 percent level and only one of the Republican variables is significant at the

\footnotetext{
${ }^{21}$ We also tried a variety of other models. We interacted all of the slope coefficients in the model with the $z_{t}$ dummy. Only two of the 24 slope dummies made a significant contribution to the system at the five percent level. Various other configurations of slope dummies were also tried with no clear support for their inclusion. We also considered a variable measuring the relative price of oil and the Alesina-Rosenthal oil shock dummy described above. Neither of these added significantly to the explanatory power of the model.

22 This quarter involved the largest quarterly drop in $\mathrm{R}$ and $\mathrm{Y}$ in the sample. See the 1981 Economic Report of the President for an account of this period.
} 
1 percent level.

Table 2 summarizes the statistical evidence for important political effects in the 15 models. ${ }^{23}$ The Democratic and Republican political variables - the same political variables as in Table 1 -are statistically significant at the 10 percent level or less in only about $1 / 3$ of the models (rows labelled $H_{0}$ ). In version ii (all models) and model 3 (all versions), the political effects are never significant.

We suspect that the political effects may still be overparameterized in this model, and that in particular, the only important political effects come in the first half of Republican administrations. The rows labelled $H_{X}$ test the hypothesis that the all the Democratic variables and the Republican variables for quarter 9 and beyond are zero. This hypothesis is only rejected once at the 10 percent level. Thus, it appears that Democratic presidential terms and the second half of Republican terms are similar and that the evidence of political effects comes from the recessions that coincide with the election of Republicans.

After removing the political variables for all but quarters - 1 through 8 for Republicans, we can test whether the remaining Republican effects are significant. This is a test of both $H_{0}$ and $H_{1}$, since any effect that is found involves a partisan difference. We label this hypothesis $H_{0,1}$. After limiting the set of included political dummies based on prior tests, the remaining political dummies for Republican for quarters -1 through 8 are jointly significant at the 10 percent level or better in 10 of 15 models. Of course, since we have tailored the set of variables to maximize the measured effects, we should make our standards more stringent. In only 2 cases are the dummies significant at the 1 percent level. The first half Republican effects are also insignificant in all versions of model 3 (involving hours). Thus, even after tailoring the set of dummy variables, the evidence in favor of political effects is mixed, at best.

A more economically interpretable view of the VARs is given in Table 3, which summarizes impulse response functions for the 15 models. For each model and

\footnotetext{
${ }^{23}$ In all of the models that include economic dummies, the test of the joint hypothesis that all the economic dummies are zero rejects at less than the 1 percent level.
} 


\begin{tabular}{|c|c|c|c|c|c|}
\hline \multirow[b]{2}{*}{ hypothesis } & \multicolumn{5}{|c|}{ model } \\
\hline & 1 & 2 & 3 & 4 & 5 \\
\hline & \multicolumn{5}{|c|}{$i:$ No economic dummies } \\
\hline$H_{0}$ & 0.07 I & 0.30 & 0.26 & 0.11 & 0.04 । \\
\hline$H_{0,1}$ & 0.04 I & $0.09 \mathrm{I}$ & 0.12 & 0.01 . & $0.07 \mathrm{I}$ \\
\hline \multirow[t]{2}{*}{$H_{X}$} & 0.35 & 0.70 & 0.55 & 0.66 & 0.15 \\
\hline & \multicolumn{5}{|c|}{ ii : Credit Control } \\
\hline$H_{0}$ & 0.20 & 0.41 & 0.39 & 0.25 & 0.12 \\
\hline$H_{0,1}$ & $0.05 \mathbf{I}$ & 0.12 & 0.20 & $0.03 \mathbf{I}$ & 0.13 \\
\hline \multirow[t]{2}{*}{$H_{X}$} & 0.63 & 0.79 & 0.63 & 0.82 & 0.28 \\
\hline & \multicolumn{5}{|c|}{ iii : Credit Control \& Bretton Woods } \\
\hline$H_{0}$ & 0.04 । & 0.18 & 0.22 & $0.05 \mathbf{I}$ & 0.01 . \\
\hline$H_{0,1}$ & $0.03 \mathbf{I}$ & 0.04 । & 0.16 & 0.01 【 & 0.05 I \\
\hline$H_{X}$ & 0.24 & 0.70 & 0.43 & 0.58 & 0.04 【 \\
\hline
\end{tabular}

Notes: $H_{0}$ : all political dummies are jointly significant. $H_{0,1}$ : after imposing $H_{X}$, all remaining political dummies $\left(r q_{-1}, \ldots, r q_{8}\right)$ are zero. $H_{X}$ : all political dummies except $r q_{-1}, \ldots, r q_{8}$ are zero. The numbers reported are marginal significance levels, the tests are as described in the notes to Table 1. I, I, I, indicate significance at the 1,5 , and 10 percent levels, respectively.

Table 2: Significance of political state variables 5 models 
version, the Table gives the averaged impulse response of $\mathrm{Y}, \mathrm{R}, \mathrm{M}$, and $\mathrm{P}$ to an election shock over the first and second halves of the presidential term. If significant output effects operate through monetary policy, we would expect to see positive output growth effects in the first half, positive money and inflation effects in both halves, and perhaps negative then positive interest rate effects.

In model 3, the effects are statistically insignificant and the point estimates are not consistent with the rational partisan story. ${ }^{24}$ The first-half output effects are smaller than the second-half effects which may be positive or negative, depending on the verison. The money growth effects are negative, and the inflation effects are also negative in two versions. Only the interest rate effect is as expected.

The first half output effects are largest and most statistically significant in versions $i$ and iii. In these versions, however, the interest rate and money growth effects are quite small, relative to the output effects. Further, the inflation effects are small, with point estimates that are often negative. Thus, while versions $i$ or iii may support important first-half output effects, they provide no support for the view that these effects operate through monetary policy.

The pattern of point estimates in version ii (especially model 1) is probably most supportive of the rational partisan theory. The second-half interest rate and inflation effects are in the right direction and the first-half output effects are generally large. The money growth effects tend to be negative in the second-half, however.

Overall, the point estimates in Table 3 and the statistical significance figures in Table 2 show no consistent pattern of support for important output effects or for output effects caused by surprise changes in monetary policy.

\section{Discussion}

This paper highlights several questions regarding standard macroeconometric and political econometric results and sheds some light on the answers to those questions.

\footnotetext{
24 In Table 3, the measure of statistical significance comes from the Bayesian bootstrapped coverage intervals, and not $\mathrm{F}$ tests.
} 


\begin{tabular}{|c|c|c|c|c|c|c|}
\hline \multirow{2}{*}{$\begin{array}{l}\text { model } \\
\text { variable }\end{array}$} & \multirow[b]{2}{*}{ half } & 1 & 2 & 3 & 4 & 5 \\
\hline & & \multicolumn{5}{|c|}{ average response } \\
\hline & & & $i:$ No ec & onomic & fummies & \\
\hline \multirow[t]{2}{*}{ Output growth } & 1 & 0.24 & 0.18 । & 0.10 & 0.18 । & 0.18 । \\
\hline & 2 & 0.04 & 0.08 & 0.10 & 0.06 & 0.06 \\
\hline \multirow[t]{2}{*}{ 3-Month T-Bill } & 1 & -0.08 & -0.12 & -0.14 & -0.14 & $-0.16 \mathrm{I}$ \\
\hline & 2 & 0.16 & 0.06 & 0.06 & 0.06 & 0.08 \\
\hline \multirow[t]{2}{*}{ Money growth } & 1 & 0.10 & -0.10 & 0.00 & -0.06 & -0.04 \\
\hline & 2 & 0.08 & 0.04 & -0.08 & 0.02 & -0.04 \\
\hline \multirow[t]{3}{*}{ CPI inflation } & 1 & -0.06 & -0.10 & -0.10 & -0.12 & -0.16 \\
\hline & 2 & 0.06 & 0.00 & -0.06 & 0.00 & 0.06 \\
\hline & & \multicolumn{5}{|c|}{$i i$ : Credit Control } \\
\hline \multirow[t]{2}{*}{ Output growth } & 1 & $0.16 \mathrm{I}$ & 0.12 & 0.00 & 0.12 & 0.16 \\
\hline & 2 & -0.10 & 0.00 & -0.06 & -0.06 & -0.04 \\
\hline \multirow[t]{2}{*}{ 3-Month T-Bill } & 1 & 0.04 & 0.00 & -0.02 & -0.02 & -0.04 \\
\hline & 2 & 0.40 I & 0.28 & 0.30 & 0.26 & 0.42 । \\
\hline \multirow[t]{2}{*}{ Money growth } & 1 & 0.00 & $-0.28 \mathrm{I}$ & -0.16 & -0.16 & -0.24 I \\
\hline & 2 & 0.16 & -0.02 & -0.12 & 0.06 & -0.22 \\
\hline \multirow[t]{3}{*}{ CPI inflation } & 1 & 0.20 । & 0.14 & 0.18 & 0.08 & 0.10 \\
\hline & 2 & 0.40 I & $0.34 \mathrm{I}$ & $0.32 \mathrm{I}$ & 0.28 & $0.46 \square$ \\
\hline & & $i i i:($ & redit $\mathrm{Co}$ & htrol \& & Bretton & Voods \\
\hline \multirow[t]{2}{*}{ Output growth } & 1 & 0.22 【 & 0.16 I & 0.08 & $0.16 \mathrm{I}$ & 0.16 I \\
\hline & 2 & 0.08 & 0.12 & 0.16 & 0.12 & 0.12 \\
\hline \multirow[t]{2}{*}{ 3-Month T-Bill } & 1 & -0.04 & -0.08 & -0.10 & -0.10 & -0.12 \\
\hline & 2 & 0.16 & 0.06 & 0.04 & 0.06 & 0.10 \\
\hline \multirow[t]{2}{*}{ Money growth } & 1 & 0.08 & -0.16 & -0.06 & -0.10 & -0.10 \\
\hline & 2 & 0.12 & 0.10 & -0.04 & 0.08 & -0.02 \\
\hline \multirow[t]{2}{*}{ CPI inflation } & 1 & -0.02 & -0.06 & -0.08 & -0.10 & -0.14 \\
\hline & 2 & 0.04 & -0.02 & -0.10 & -0.04 & 0.04 \\
\hline
\end{tabular}

Notes: Half 1 is quaters -1 through 8 ; half 2 is quarters 9 through 15 . The impulse response is averaged over the relevant half. The symbols are as in Table 2 . In this table, a quantity is significantly different from zero at, say, the 10 percent level if the interval between the $5^{t h}$ and $95^{t h}$ percential points from the Bayesian bootstrap (described in the text) does not cover zero.

Table 3: Summary of impulse response to election shock 
On the negative side, it is clear that correlations among political variables and a wide range of macroeconomic variables at both leads and lags renders unreliable results from univariate work treating political variables as exogenous. We provide a framework for sorting out these interactions.

Applying this framework, we conclude that there is some weak and fragile evidence in favor of important political effects. The strongest evidence seems to come from the first half of Republican administrations: recessions have followed the election of Republicans and macroeconomic factors alone may not account for this fact. There is little evidence, however, that the causal explanation of any political effects on the economy operates through surprise changes in monetary policy.

These results should be viewed as a challenge to those who believe that we have clear evidence of political effects, but not proof that there are no such effects. A balanced conclusion is that the political effects are not large and systematic enough to be easily and precisely measured. Finding such effects will either require putting more structure on the problem in the form of a priori assumptions, using more powerful statistical methods, or bringing different information to bear. 


\section{Appendix}

The method for calculating the impulse response can be seen from the augmented VAR. The expected path of the economy at the end of $t-1$ can be written,

$$
\begin{aligned}
E_{t-1} X_{j t+i}=\quad & E_{t-1}\left[X_{j t+i} \mid z_{t+1}=1\right] E_{t-1}\left[z_{t+1}\right]+ \\
& E_{t-1}\left[X_{j t+i} \mid z_{t+1}=0\right]\left(1-E_{t-1}\left[z_{t+1}\right]\right)
\end{aligned}
$$

Since $\partial E_{t-1}\left[z_{t+1}\right] / \partial E_{t-1} u_{t}=1$,

$$
\frac{\partial E_{t-1} X_{j t+i}}{\partial E_{t-1} u_{t}}=E_{t-1}\left[X_{j t+i} \mid z_{t+1}=1\right]-E_{t-1}\left[X_{j t+i} \mid z_{t+1}=0\right]
$$

which is simply the difference in the expected path of the economy under the two parties. For $i<15$, this expression can be evaluated simply from the augmented VAR and does not depend on $\Phi$ or the $z_{t}$ equation.

Expression (8) is easy to evaluate. Similar to the calculation of impulse responses in a standard VAR, the impulse response to election shocks can be calculated as the difference in a dynamic simulation of the model under the two possible outcomes for the election.

\section{Data}

All economic data (except M1 and M2 for the period before 1959) are from the Federal Reserve's U.S. database. All growth rates are computed as the annualized quarterly change in the logarithm of the variable. The data series are GNP, personal consumption expenditures, gross private domestic investment, and federal government purchases of goods and services from the GNP accounts, all in 1987 dollars. The unemployment rate is for civilian males 20 years or older; hours are for all persons in the nonfarm business sector. M1 and M2 are not seasonally adjusted; the pre-1959 data were constructed by Robert Rasche. The Three-month T-Bill rate is a yield from the secondary market. The inflation rate is for the CPI, all urban consumers. The two commodity price indices are the producer price index for intermediate materials and sensitive materials. All of the dummy variables were constructed by the author. All data are available on request. 


\section{References}

Alesina, A., 1987. Macroeconomic policy in a two-party system as a repeated game, Quarterly Journal of Economics, 102, 651-678.

Alesina, A., 1991. Evaluating Rational Partisan Business Cycle Theory: A Response. Economics and Politics, 3, 63-71.

Alesina, A. and N. Roubini, 1992. Political Cycles in OECD Economies. Review of Economic Studies, 59, 663-688.

Alesina, A. and H. Rosenthal, 1995. Partisan politics, divided government and the economy, Cambridge University Press: New York.

Alesina, A., J. Londregan and H. Rosenthal, 1993. A Model of the Political Economy of the United States. American Political Science Review, 87 (1), 12-33.

Alesina, A., and J. Sachs, 1987. Political Parties and the Business Cycle in the United States, 1948-1984. Journal of Money, Credit, and Banking, 20, 63-82.

Allen, S., 1986. The Federal Reserve and the Electoral Cycle. Journal of Money, Credit, and Banking, 18, 88-94.

Allen, S. and D. McCrickard, 1991. The Influence of Elections on Federal Reserve Behavior, Economics Letters, 37, 51-55.

Bange, M., W. Bernhard, and J. Granato, 1995. Partisan Monetary Policy, Inflation, and Economic Growth. Michigan States University's Institute for Public Policy and Social Research Working Paper 95-04.

Beck, N., 1982. Presidential Influence on the Federal Reserve in the 1970s. American Journal of Political Science, 26, 415-445.

Beck, N., 1982. Parties, Administrations, and American Macroeconomic Outcomes. The American Political Science Review, 76, 83-93.

Bernanke, B. and A. Blinder, 1992. The Federal Funds Rate and the Channels of Monetary Transmission. American Economic Review, 82, September, 681-21.

Bizer, D., and S. Durlauf, 1990. Testing the positive theory of government finance. Journal of Monetary Economics, 26, 123-141.

Browning, R., 1985. Presidents, Congress, and Policy Outcomes: US Social Welfare Expenditures, 1949-77. American Journal of Political Science, 29, 197-216.

Chapell, H., and W. Keech, 1986. Party Differences in Macroeconomic Policies and Outcomes. American Economic Review, 76, 71-74. 
Christiano, L. and M. Eichenbaum, 1992. Identification and the Liquidity Effect of a Monetary Policy, in Political economy, growth, and business cycles, (Cukierman, A., et al. eds.), MIT press, Cambridge and London, 335-70.

Christiano, L., M. Eichenbaum, and C. Evans, 1994. The effects of monetary policy shocks: some evidence from the flow of funds, NBER Working paper \#4699.

Doornik, J. and D. Hendry, 1994. PcFiml 8.0. Interactive Econometric Modelling of Dynamic Systems. International Thomson: London.

Economic Report of the President, 1981. U.S. Government Printing Office.

Ellis, C., and M. Thoma, 1991. Causality in Political Business Cycles. Contemporary Policy Issues, 9. 39-49.

Faust, J. and J. Irons. 1996. Politics, policy, and the economy, manuscript, Federal Reserve Board.

Faust, J. and E. Leeper. 1993. When do long-run identifying restrictions give reliable results? Manuscript Federal Reserve Board.

Fair, R., 1978. The Effect of Economic Events on Votes for President. The Review of Economics and Statistics, 60, 159-173.

Fair, R., 1982. The Effect of Economic Events on Votes for President: The 1980 Results. The Review of Economics and Statistics, 62, 322-325.

Frey, B., and F. Schneider, 1978. An Empirical Study of Politico-Economic Interaction in the United States. The Review of Economics and Statistics, 60, 174-183.

Friedlaender, A., 1973. Macro Policy Goals in The Postwar Period: A Study in Revealed Preference. Quarterly Journal of Economics, 87, 25-43.

Friedman, M., and A. Schwartz, 1963. A Monetary History of the United States 1867-1960, Princeton, NJ: Princeton University Press, 1963.

Gallant, R, P. Rossi, and G. Tauchen, 1993. Nonlinear dynamic structures, Econometrica, 61, 871-907.

Gartner. M., and K. Wellershoff, 1991. Theories of Political Cycles: Lessons From the American Stock Market. Paper delivered at the January 1992 Annual Meetings of the American Economic Association, New Orleans.

Gleisner, R., 1992. Economic determinants of presidential elections: the Fair model, Political Behavior, 14, 383-394.

Golden, D., and J. Poterba, 1980. The Price of Popularity: The Political Business Cycle Reexamined. American Journal of Political Science, 24, 696-714. 
Gordon, D. and E. Leeper, 1994. The Dynamic Impacts of Monetary Policy: An Exercise in Tentative Identification. Journal of Political Economy, 102, December.

Granato, J., and W. West, 1994. Words and Deeds: Symbolic Politics and Decision Making at the Federal Reserve. Economics \& Politics, 6, 233-255.

Granato, J., and Suzuki. Undated. The use of the encompassing principle to resolve empirical controversies in voting behavior, manuscript, Michigan State University.

Hamilton, H., 1985. Historical Causes of Postwar Oil Shocks and Recessions. The Energy Journal, 6, 97-116.

Hansen, L. P., and Sargent, T. J., 1991b. Identification of Continuous Time Rational Expectations Models from Discrete Time Data, in Rational Expectations Econometrics, L. P. Hansen and T. J. Sargent (eds.), Boulder, CO: Westview Press, 219-238.

Havrilesky, T., and J. Gildea, 1991a. The Policy Preferences of FOMC Members as Revealed by Dissenting Votes. Journal of Money, Credit, and Banking, 23, $130-137$.

Havrilesky, T., and J. Gildea, 1991b. Screening FOMC Members for their Biases and Dependability. Economics \& Politics, 3, 139-149.

Haynes, S, and J. Stone, 1989. An Integrated Test for Electoral Cycles in The U.S. Economy. The Review of Economics and Statistics, 71, 426-434.

, 1990. Political Models of the Business Cycle Should Be Revived. Economic Inquiry, 28, 442-465.

, 1994. Why Did Economic Models Falsely Predict a Bush Landside in 1992? Contemporary Economic Policy, 12, 123-130.

Hendry, D., 1995. Dynamic Econometrics, Wiley and Sons: New York.

Hess, G., 1993. Are Tax Rates Too Volatile? Southern Economic Journal, 60 (1), $72-88$.

Hibbs, D., 1977. Political Parties and Macroeconomic Policy. The American Political Science Review, 71, 1467-1487.

Hibbs, D., 1987. The American Political Economy: Macroeconomics and Electoral Politics. Harvard University Press: Cambridge.

Hoover, K. and S. Perez, 1994a. Post Hoc Ergo Propter Hoc Once More: An Evaluation of "Does Monetary Policy Matter?" in the Spirit of James Tobin. Journal of Monetary Economics, 34, August. 
, 1994b. Money May Matter, But How Could You Know? Journal of Monetary Economics 34, August.

Klein, M., 1993. Timing is All: Elections and The Duration of United States Business Cycles, 1993. Manuscript, Tufts University.

Leeper, E., 1993. Has the Romers' Narrative Approach Identified Monetary Policy Shocks? Manuscript, Federal Reserve Bank of Atlanta.

Leeper, E. and D. Gordon, 1992. In Search of the Liquidity Effect,Journal of Monetary Economics, 29, 341-69.

Lehmann, E., 1986. Testing statistical hypotheses. John Wiley: New York.

Marcet, A., 1991, Temporal Aggregation of Economic Time Series, in Rational Expectations Econometrics, L. P. Hansen and T. J. Sargent (eds.), Boulder, CO: Westview Press, 237-282.

MacRae, C., 1977. A Political Model of the Business Cycle. Journal of Political Economy, 85, 239-263.

McCallum, B., 1978. The Political Business Cycle: An Empirical Test. Southern Journal of Economics, 44, 504-515.

McManus, D., 1992. How common is identification in parametric models? Journal of Econometrics, 53, 5-23.

Nordhaus, W., 1975. The Political Business Cycle. Review of Economic Studies, 42, 169-190.

Richards, D., 1986. Unanticipated Money and the Political Business Cycle. Journal of Money, Credit, and Banking, 18, 447-457.

Romer, C. and D. Romer, 1989. Does Monetary Policy Matter? A New Test in the Spirit of Friedman and Schwartz, in Blanchard, Olivier J. and Stanley Fischer, eds., NBER Macroeconomics Annual 1989 (Cambridge: MIT), 121-70.

, 1990. New Evidence on the Monetary Transmission Mechanism, Brookings Papers on Economic Activity 1, 149-98.

Economics 34, August.

, 1994. Monetary Policy Matters. Journal of Monetary

Runkle, D., 1987. Vector Autoregressions and reality, Journal of Business Economics and Statistics, 5, 437-442.

Sims, C., 1980a. Macroeconomics and Reality, Econometrica, 48, 1-48. 
Sims, C. 1980b. Comparison of Interwar and Postwar Business Cycles: Monetarism Reconsidered, Papers and Proceedings of the American Economic Association $70,250-57$.

Sims, C., 1992. Interpreting the macroeconomic time series facts, European Economic Review 36, 975-1011.

Sims, C. and T. Zha, 1994. Does Monetary Policy Generate Recessions?: Using Less Aggregated Price Data to Identify Monetary Policy, manuscript, Yale University.

Sims, C. and T. Zha, 1994. Error bands for impulse responses, manuscript, Yale.

Soh, B., 1986. Political Business Cycles in Industrialized Democratic Countries. KYKLOS, 39, 31-46.

Stigler, G., 1973. General economic conditions and national elections, American Economic Review, 63, 160-167.

Strongin, S., 1995. The Identification of Monetary Policy Disturbances: Explaining the Liquidity Puzzle, Journal of Monetary Economics, 35, 463-97.

Tufte, E., 1978. Political Control of the Economy, Princeton University Press: Princeton. 
Figure 1: Mean unemployment rate by quarter of term and party

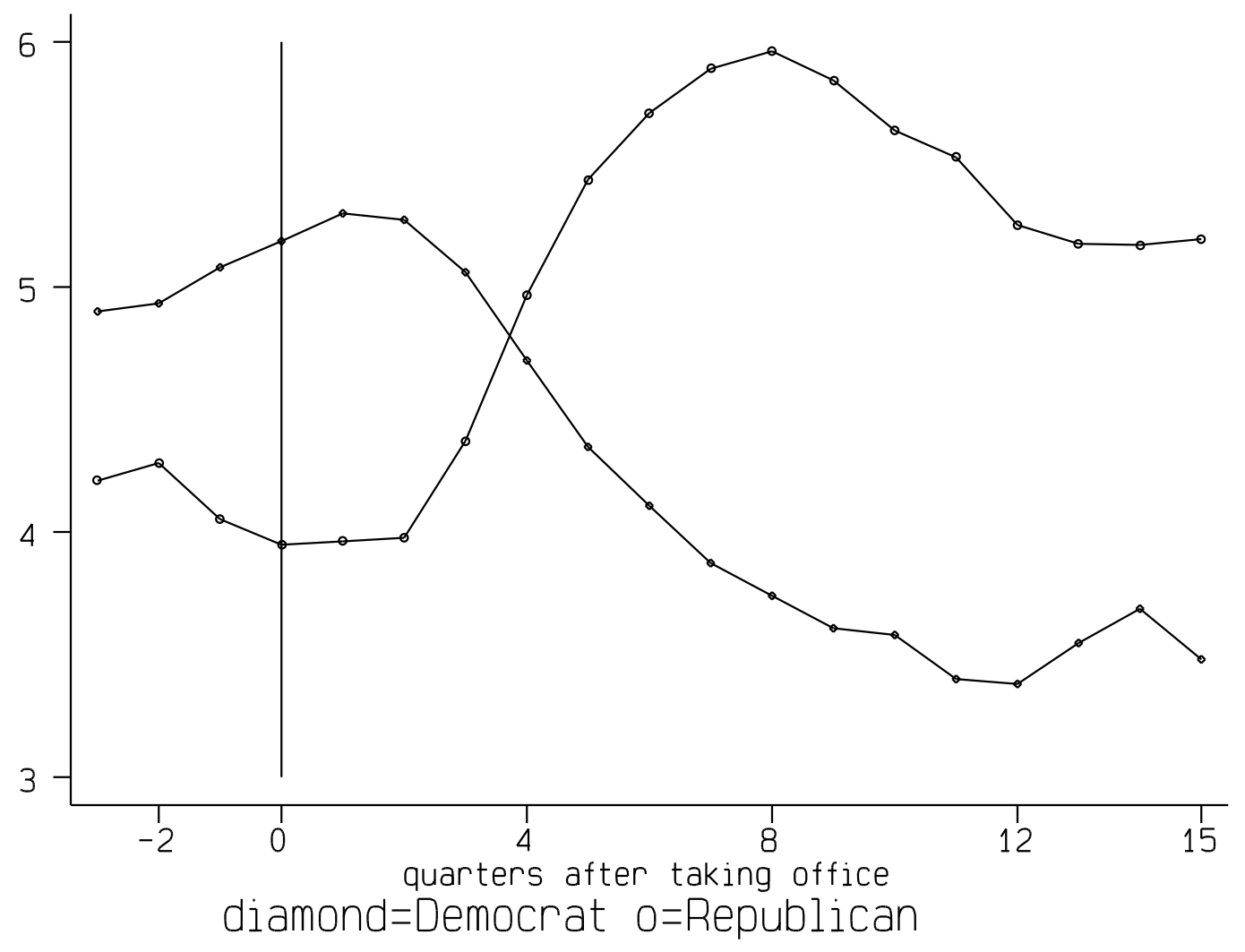




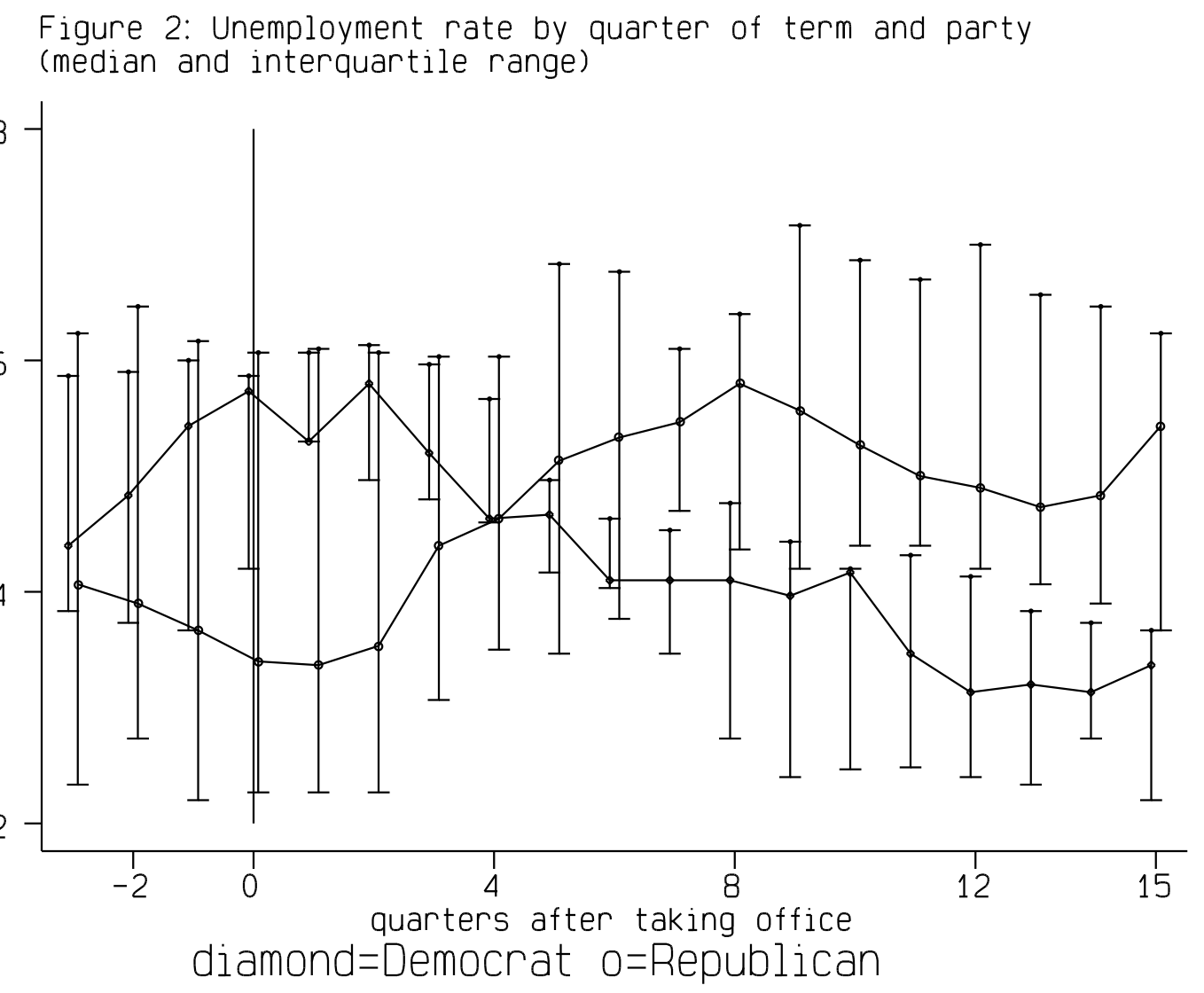


Figure 3: Growth in hours by quarter of term and party (median and interquartile range)

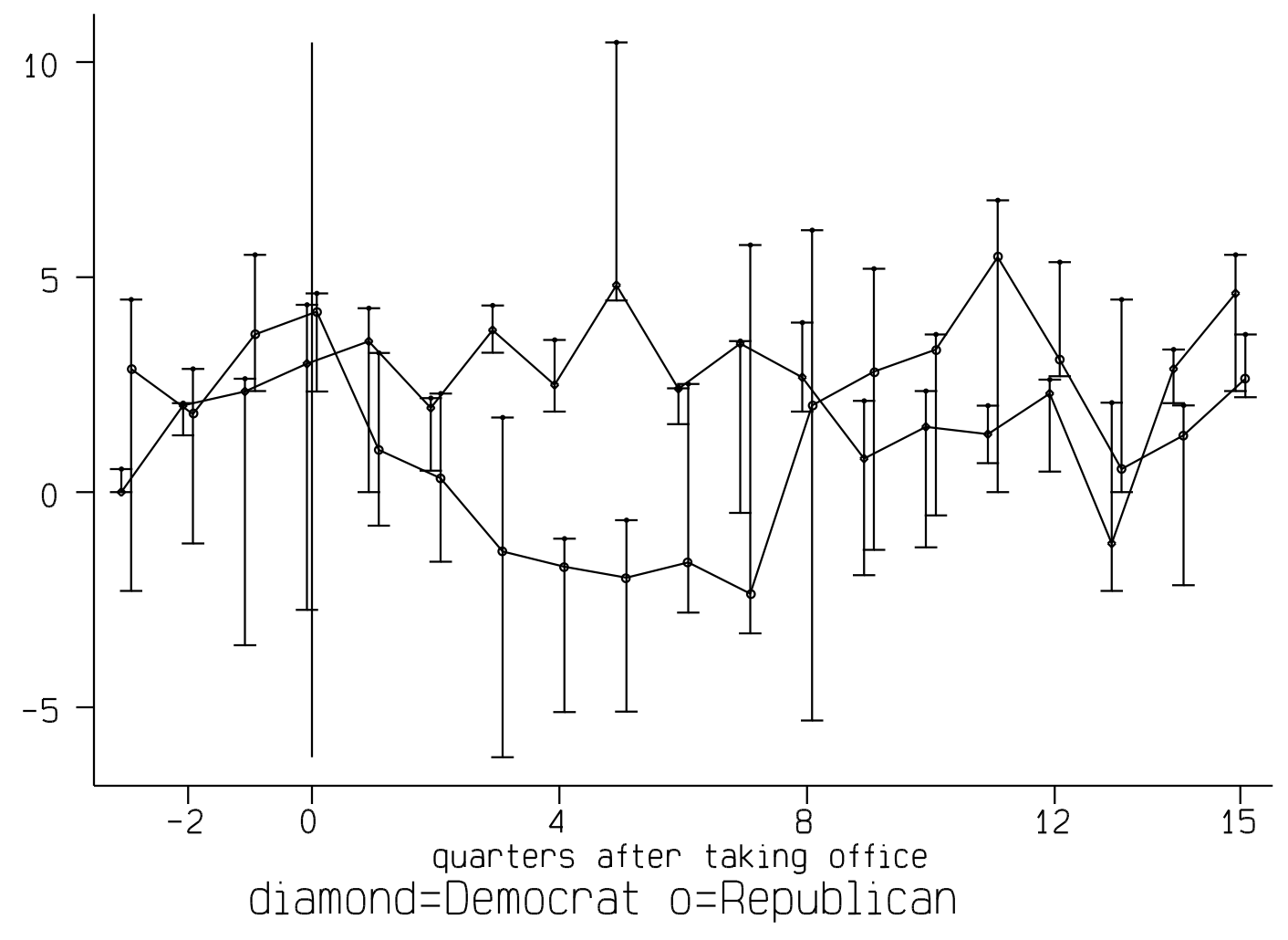




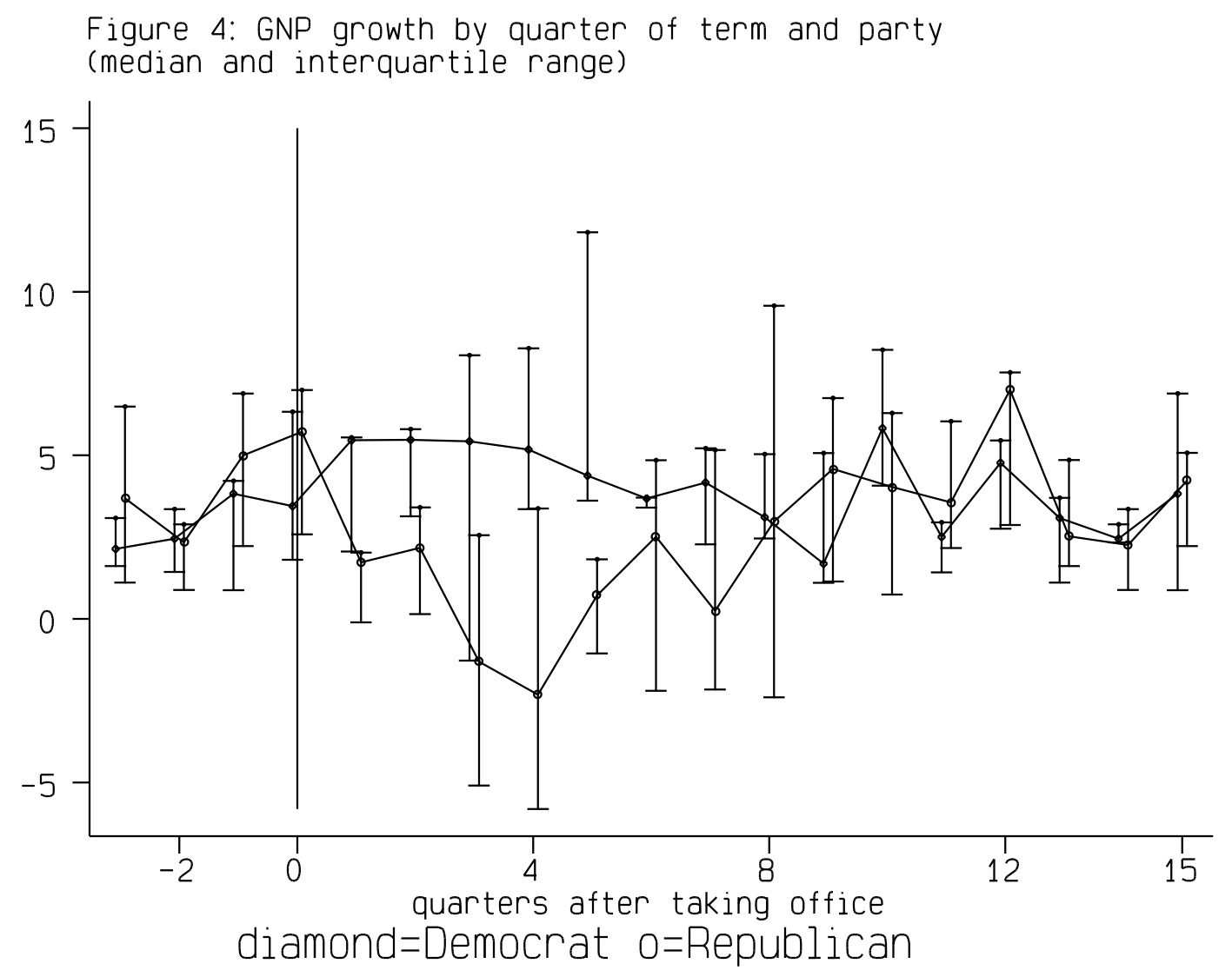


Figure 5: 3-month Treasury bill rate by quarter of term and party (median and interquartile range)

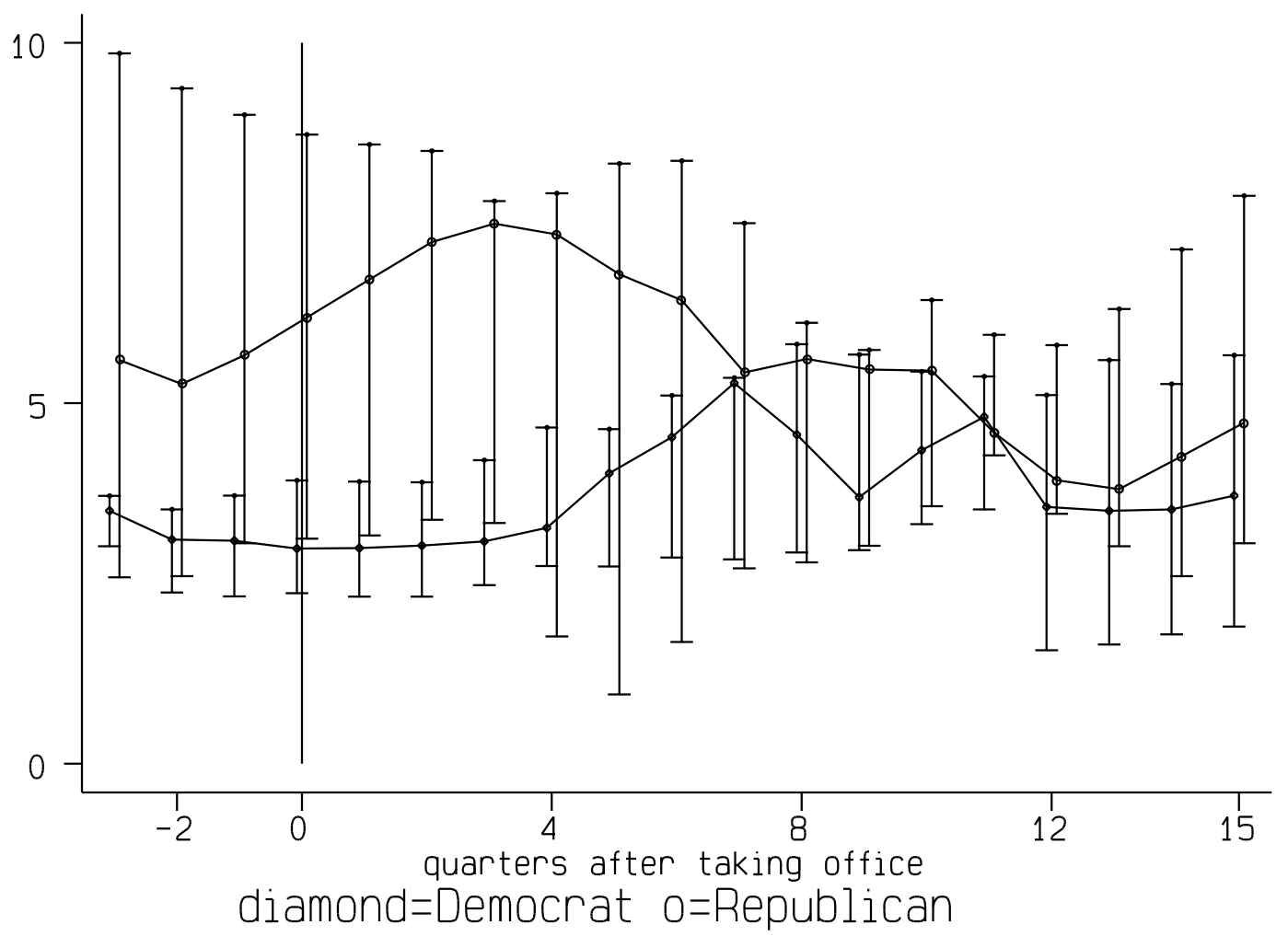


Figure 6: CPI inflation by quarter of term and party (median and interquartile range)

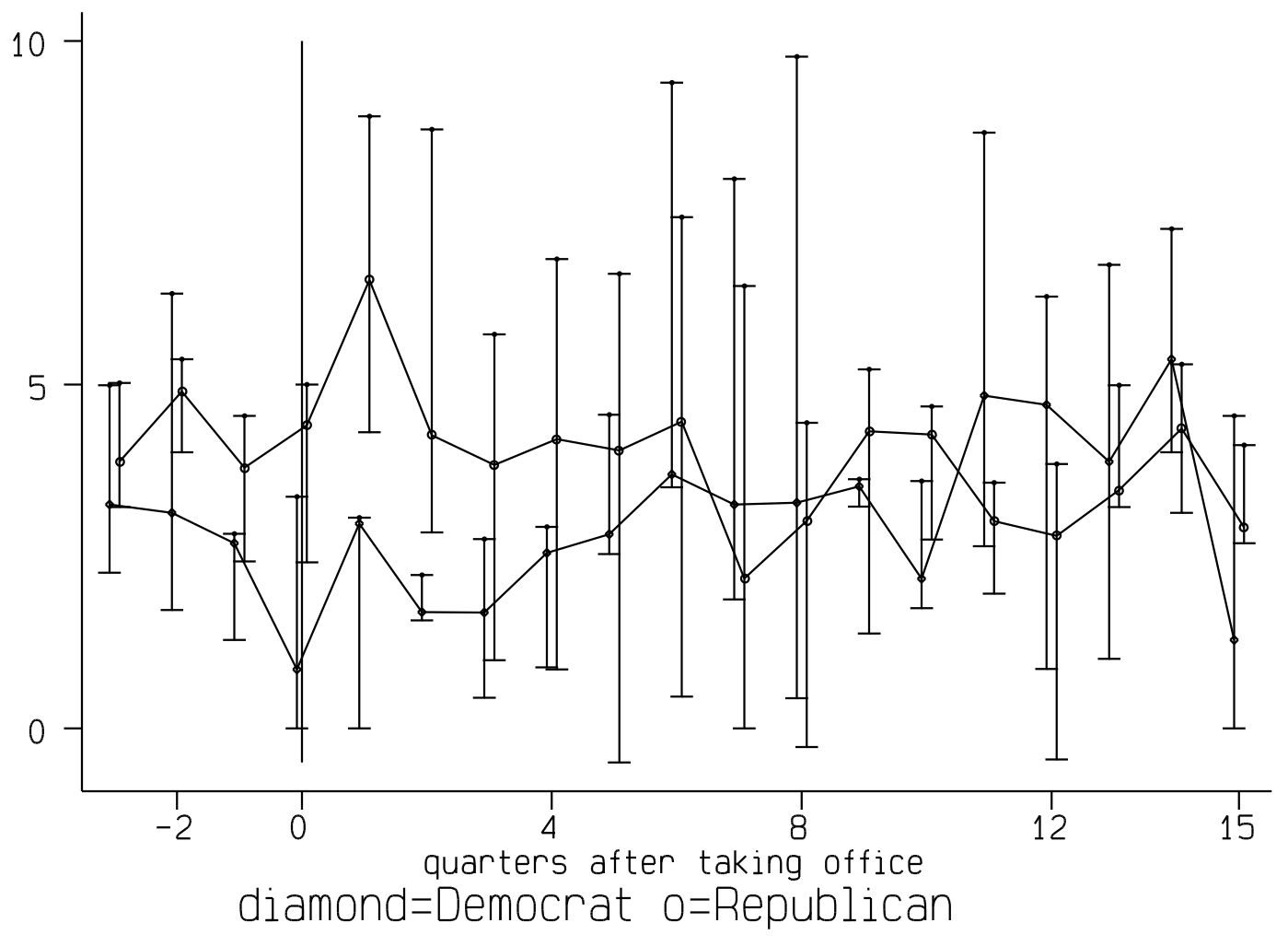




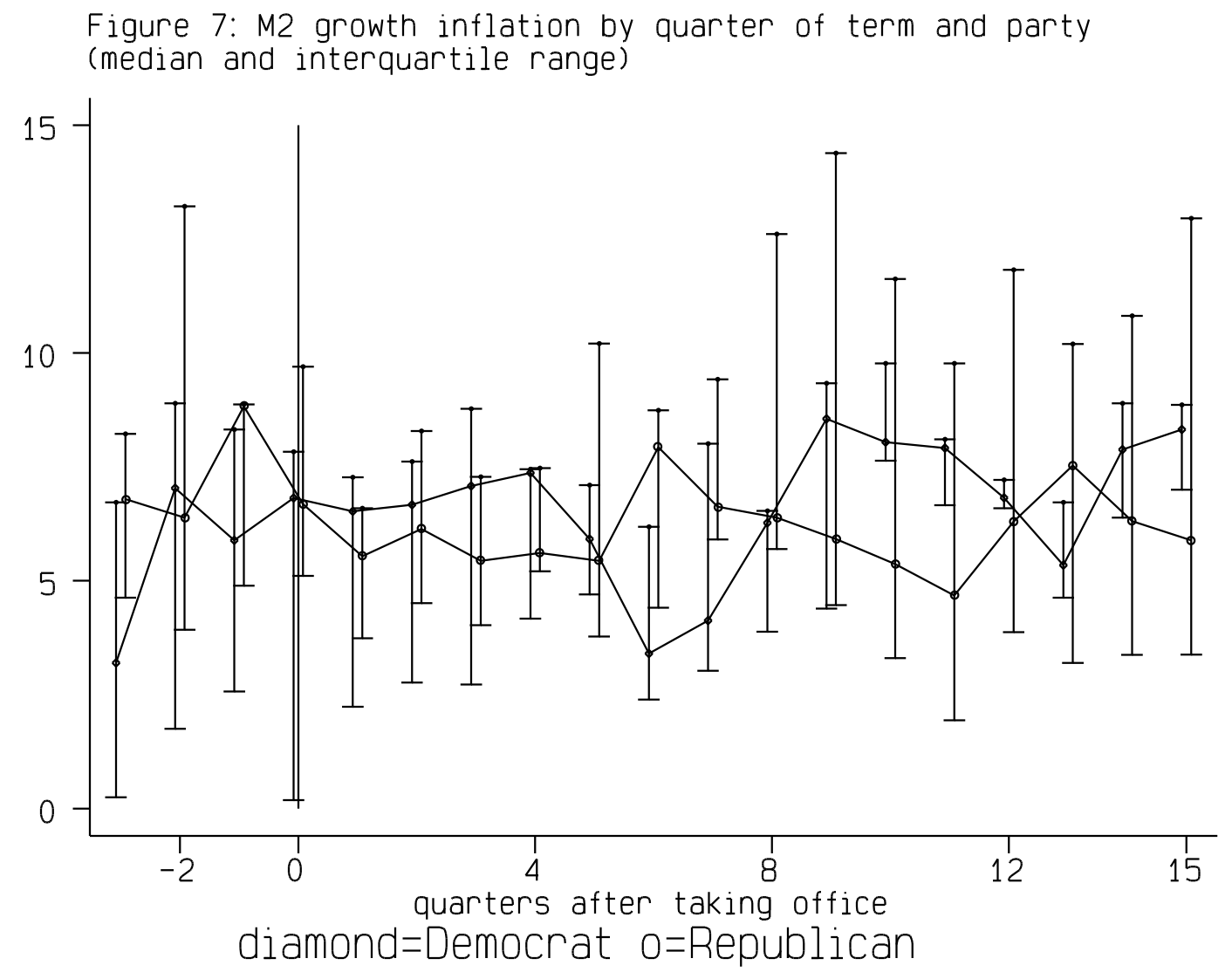


Figure 8: Response to 10 percentage point Democratic surprise (5th-95th percential Bayesian bootstrap band) GNP growth
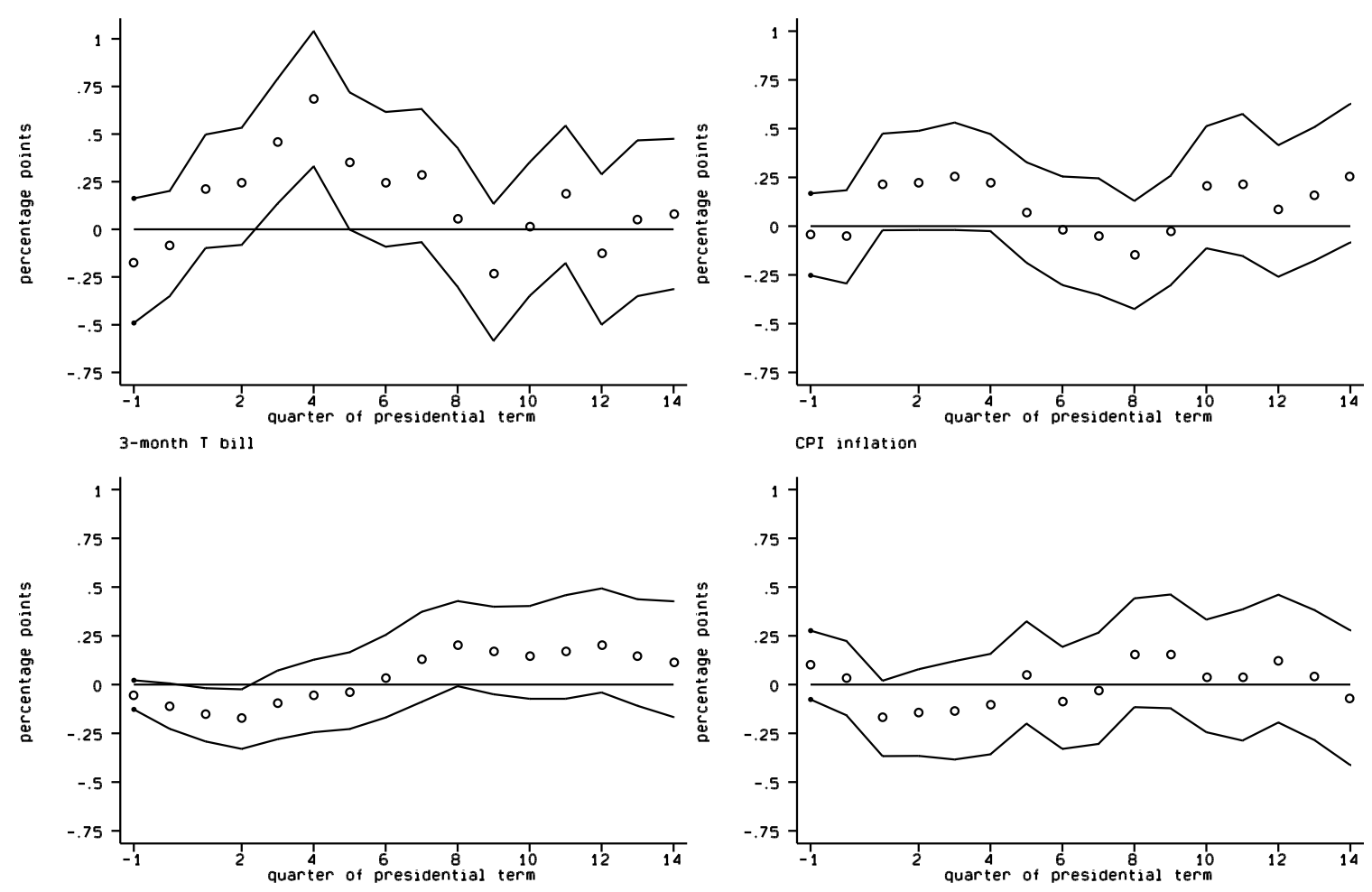